\title{
Bone morphogenetic proteins and spinal fusion
}

\author{
David H. Walker, M.D., AND Neill M. Wright, M.D. \\ Department of Neurosurgical Surgery, Washington University School of Medicine, St. Louis, Missouri
}

\begin{abstract}
Bone morphogenetic proteins (BMPs) have increasingly become a focus of research in the laboratory, with animal models, and in human clinical trials for the treatment of spinal disorders. Basic science research has elucidated the putative mechanism of action of BMPs, and the efficacy of BMPs in inducing bone formation has been evaluated in multiple animal models of anterior and posterior spinal fusion. Not only has BMP been shown to improve the quality and amount of bone formation when used as a supplement to autograft, it has also been shown to promote superior fusion in the absence of autograft, even in high-risk fusion models involving the use of nicotine or nonsteroidal antiinflammatory agents. Both completed and ongoing clinical trials have demonstrated the efficacy of recombinant BMP, leading to the first BMP product being approved for clinical use earlier this year.

Animal models and clinical trials have also been used to evaluate the safety of BMPs. Although few complications have been reported, BMPs can induce heterotopic bone formation, especially when placed adjacent to exposed neural elements. Potentially more serious, antibody formation has been seen in up to $38 \%$ of patients in some clinical trials. No clinical sequelae have been reported despite the development of antibodies against BMP, a naturally occurring human protein implicated in processes other than osteoinduction.

The future directions of biological manipulation of the osteoinduction process include further understanding of the interactions of the BMP subtypes, the interactions of BMP with its receptors, and exploring other molecules capable of osteoinduction.
\end{abstract}

\section{KEY WORDS • bone morphogenetic protein • osteoinduction • spinal fusion}

Bone morphogenetic proteins have dramatically changed the landscape of spinal surgery since their introduction nearly three decades ago. Initially described by Dr. Marshall Urist in 1965, the BMP family has generated an ever increasing flurry of scientific research, animal studies, and clinical trials during the past few decades. This year, the first recombinant BMP product approved by the FDA for use in spinal surgery was released, and several other BMP products are currently undergoing clinical trials for the treatment of spinal disorders.

With the advent of recombinant protein use in the field of spinal surgery, the surgeon must necessarily be familiar with the basic science behind the mechanisms of BMP, as well as with the wealth of data from animal and clinical studies supporting the judicious use of BMP. Although BMP promises an exciting new era for spinal surgery, the uninformed use of BMP - as with any rh protein used as

Abbreviations used in this paper: ALIF = anterior lumbar interbody fusion; $\mathrm{BMP}=$ bone morphogenetic protein; $\mathrm{CT}=$ computerized tomography; DBM = demineralized bone matrix; FDA = Food and Drug Administration; GDF = growth and differentiation factor; NSAID = nonsteroidal antiinflammatory medication; $\mathrm{OP}=$ osteogenic protein; PLIF = posterior lumbar interbody fusion; PLIT = posterolateral intertransverse lumbar fusion; $r=$ recombinant; $r h=$ recombinant human. a treatment tool-may result in clinical complications. It is not enough to know that BMP induces bone formation; the surgeon should understand how BMP promotes osteogenesis and in which situations it should and should not be used.

Toward this end, this paper reviews the historical background of the discovery and development of BMP as well as the known mechanisms of BMP-induced osteogenesis. Additionally, relevant animal studies are examined and the major clinical trials are discussed, as are the known possible adverse effects of BMP use.

\section{HISTORICAL BACKGROUND}

In 1965, Dr. Marshall R. Urist ${ }^{66}$ initially reported on the ability of demineralized bone matrix to induce in-growth of connective tissue and differentiation of cartilage and bone when implanted in extraskeletal locations in the rat. Urist ultimately extracted a glycoprotein from this demineralized bone matrix capable of osteoinduction: the first BMP. ${ }^{68}$ As defined by Urist, osteoinduction is the "process of recruitment of mesenchymal-type cells into cartilage and bone under the influence of a diffusible bone morphogenetic protein." ${ }^{\circ 7}$ Since that initial report, nearly 30 BMPs have been identified, at least nine of which have proven osteoinductive effects. ${ }^{52}$ 
Bone morphogenetic proteins have since been characterized as secreted polypeptides that have effects on a multitude of cell lineages. All but BMP-1 are members of the transforming growth factor- $\beta$ superfamily. Although BMP-1 was isolated with other BMP subtypes, it is considered a separate class of protein as its biological effects are quite different. ${ }^{26}$ Many of the BMP subtypes were independently characterized prior to their recognition as belonging to the BMP family and therefore have been named with alternative terminology as OPs or as GDFs (Table 1 ). Most notably, BMP-7 is synonymous with OP- 1 . Bone morphogenetic proteins are further divided into groups based on their primary amino acid sequences: BMP-2 and BMP-4; BMP-3 and BMP-3b; BMP-5 through BMP-8; BMP-9 and BMP-10; BMP-11; BMP12 through BMP-14 (R \& D Systems, Inc., Minneapolis, MN).

Native BMP is present in bone in minute amounts: less than $2 \mathrm{mg} / \mathrm{kg}$ in cortical bone and approximately $1 \mathrm{mg} / \mathrm{kg}$ of fresh wet bone..$^{50}$ Extraction is difficult and not predictable. ${ }^{52}$ In 1988, Wozney, et al. ${ }^{70}$ successfully cloned BMP-1 through 4 and other BMPs have since been cloned. With the application of rDNA technology, large amounts of rhBMP are now available for research and clinical use. Recombinant protein production also removes the issues of transmissible disease inherent in extraction from human tissue.

Although named BMPs because of the osteoinductive effects noted by Urist, this protein family is misnamed. Bone morphogenetic proteins have been shown to have significant effects other than osteoinduction in a variety of cell lineages. Invertebrate evidence suggests that the BMP family directs limb patterning. ${ }^{27,47}$ Expression of BMP or the BMP receptors has also been implicated in nervous system development ${ }^{35,42}$ as well as in pathological processes such as atherosclerosis, ${ }^{8}$ primary pulmonary hypertension, ${ }^{44}$ and prostate cancer. ${ }^{28}$ Mutations of $B M P$ genes can lead to developmental anomalies such as autosomal dominant-fibrodysplasia ossificans progressiva. ${ }^{52}$

\section{MOLECULAR BIOLOGY}

The BMP family proteins are synthesized as a prepropeptides that range in size from 400 to 500 amino acids.

TABLE 1

Nomenclature of the BMP subtypes

\begin{tabular}{ll}
\hline \hline BMP & Alternative \\
\hline BMP-2 & \\
BMP-3 & osteogenin \\
BMP-3b & GDF-10 \\
BMP-4 & BMP-2b \\
BMP-5 & \\
BMP-6 & \\
BMP-7 & OP-1 \\
BMP-8 & OP-2 \\
BMP-9 & OP-3 \\
BMP-10 & \\
BMP-11 & \\
BMP-12 & GDF-7 \\
BMP-13 & GDF-6 \\
BMP-15 & GDF-9b \\
\hline
\end{tabular}

The mature $\mathrm{COOH}$-terminal segment is secreted as a 100 to 140-amino acid unit after cleavage of the variable length prosegment, ${ }^{22}$ although some evidence suggests that the precursor protein is secreted prior to final proteolytic cleavage. ${ }^{26}$ The amino acid sequences of the mature segment of the different BMP subtypes vary, although seven cysteines are typically conserved with the structure of each BMP subtype, determined primarily by the location of these cysteine residues. After secretion, BMP dimerizes through a single interchain disulfide bond and becomes biologically active. Although it typically forms a homodimer, biologically active multimers ${ }^{61}$ and heterodimers ${ }^{54}$ have been reported.

Several distinct BMP receptors have been identified, which are composed of two main types of transmembrane serine/threonine kinases. Type I receptors are the main effector component of the ligand-receptor complexes, activating intracellular messengers. Seven different Type I receptors have been identified, with BMP-2 and BMP-4 binding BMP-Ia and BMP-Ib receptors and BMP-7 binding ALK-2 and BMP-Ib receptors. ${ }^{26}$ Type I receptors have low affinity for BMP unless they are in the presence of Type II receptors, at which time the affinity for BMP greatly increases (Fig. 1).

Type II BMP receptors are constitutively active kinases that transphosphorylate Type I receptors on ligand binding. ${ }^{16}$ Although both Type I and Type II receptors can bind BMP ligand, their affinity for BMP is relatively low unless both receptors are present. Optimal binding of BMP occurs in the presence of both Type I and II BMP receptors.

Once both Type I and II BMP receptors have bound BMP, Type II receptors transphosphorylate Type I. The phosphorylated Type I receptor in turn phosphorylates several intracellular messengers: Smads 1, 5, and 8. The pattern of Smad activation depends on which Type I BMP receptor is activated. The intracellular Smads 1 and 5 are activated by BMP-Ia and BMP-Ib receptors, whereas Smads 1,5 , and 8 are activated by ALK-2 receptors. ${ }^{26}$ Inhibitory Smads (6 and 7) have been shown to inhibit BMP-induced osteoinduction. Inhibitory Smad expression is increased in response to BMP-2 stimulation, suggesting a negative feedback pathway. ${ }^{41}$ With multiple receptor subtypes and multiple intracellular messengers, the BMP signaling system has tremendous range and variability, allowing different messages in different cell lines or even within a single cell depending on the recruitment of different receptors by various BMP ligands.

After phosphylation, the receptor Smads form heteromeric complexes with Smad-4, a co-Smad, prior to translocation into the cell nucleus. ${ }^{16,41}$ Once within the nucleus, transcription is activated; the pattern of transcription depends on the cell line and the ligand used. In mesenchymal bone marrow stem cells, increased gene expression of type I collagen, osteopontin, and osteocalcin results from exposure to BMP-2. ${ }^{10,51}$ Through receptor stimulation and selective gene expression, rhBMP-2 induces osteoinduction by first recruiting mesenchymal stem cells and then inducing the proliferation and differentiation of these cells into an osteoprogenitor lineage. ${ }^{20}$ After incubation with rhBMP-2, mesenchymal bone marrow cells have increased alkaline phosphatase activity and 


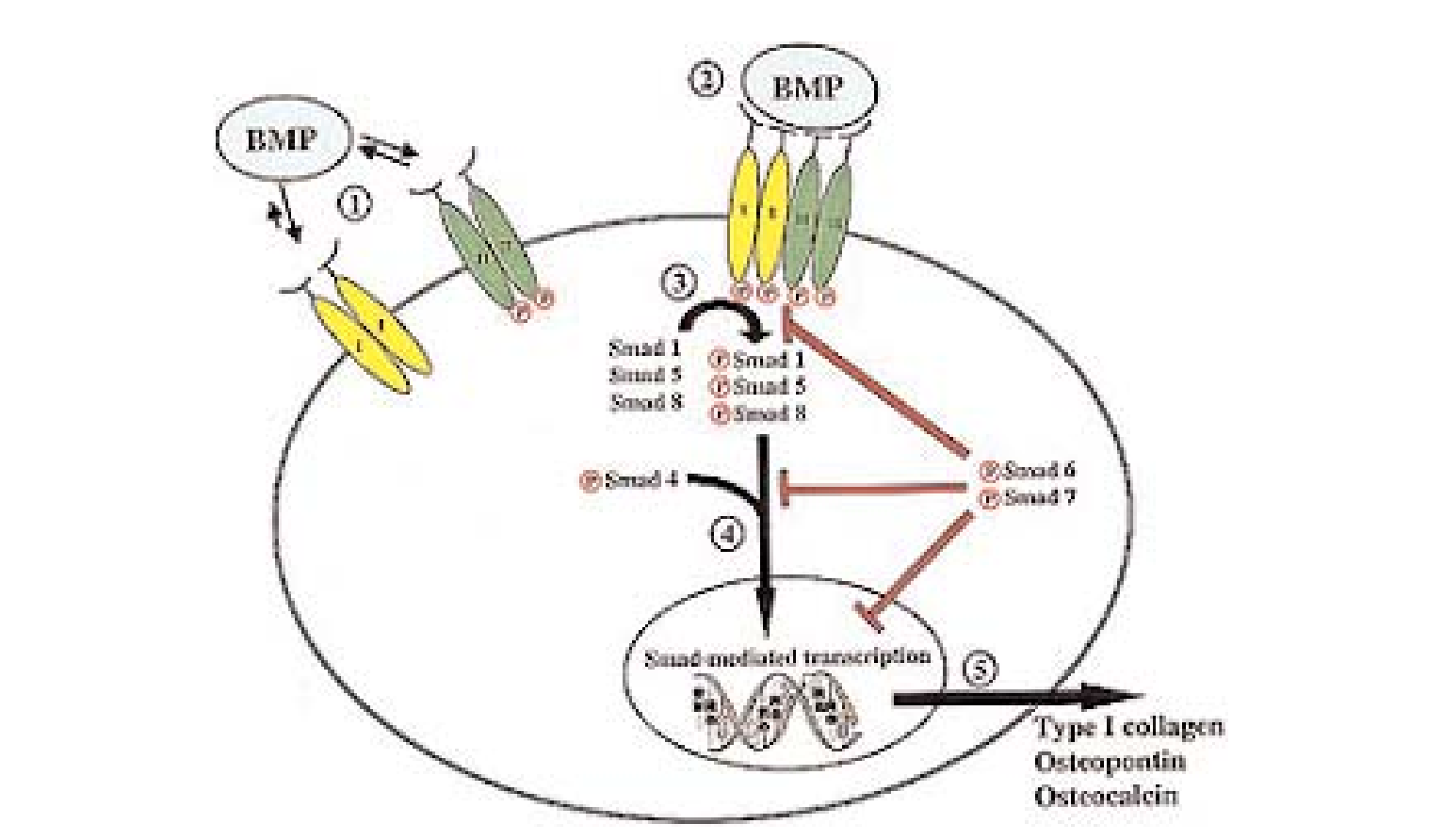

Fig. 1. Schematic drawing showing the cellular mechanisms of BMP-induced osteoinduction in a mesenchymal bone marrow stem cell. 1 = Homodimers of Type I and Type II BMP receptors exist independently in the cell membrane. Although both receptors have poor affinity for BMP in their native state, Type I has better affinity than Type II. Type II receptors are constitutively phosphorylated and both types of receptors are serine/threonine kinases. $2=$ Optimal activation occurs within a complex of BMP, Type I, and Type II receptors. Complexes of Type I and Type II receptors have strong affinity for BMP. On activation by BMP, Type II receptors transphosphorylate type I receptors. $3=$ Intracellular messengers (Smads) are phosphorylated into active forms by phosphorylated Type I BMP receptors. Depending on the specific BMP ligand and the specific Type I BMP receptor, various receptor-Smad proteins are activated. Osteoinduction primarily is signaled by Smads 1, 5, and 8.4 = Activated Smads localize across the nuclear membrane after association with activated Smad-4, a critical cofactor. 5 = Once within the nucleus, Smad proteins induce specific gene expression. Different genes are transcribed depending on the species of Smad protein activated. In mesenchymal marrow cells, BMP2 induces the expression of type I collagen, osteopontin, and osteocalcin. Although the entire feedback process is not yet understood, inhibitory Smads are also activated by phosphorylation. Smads 6 and 7 competitively inhibit the phosphorylation of receptor-Smads, compete for Smad-4, and inhibit Smad-mediated transcription.

are able to undergo matrix mineralization in vitro; ${ }^{10,51}$ both are indicators of osteoinductive capability.

\section{ANIMAL STUDIES OF BMP}

With the availability of rBMP, experimental animal systems were developed to confirm the osteoinductive effects of BMP and to optimize its later use in human trials. These animal studies have been previously reviewed ${ }^{58}$ and will only be briefly mentioned here. These animal models can be subdivided by the type of animal used, the surgical procedure performed, the subtype of BMP used, and by the system used to deliver BMP.

Initial experiments with BMP were in extraspinal animal models. Yasko, et al., ${ }^{71}$ showed structural bone formation in a dose-related response to rhBMP-2, by using an established rat segmental femoral defect. Toriumi, et al., ${ }^{65}$ demonstrated in a canine mandibular defect model the ability of BMP-2 to induce bone formation within a bone of intramembranous origin. Similar activity has also been demonstrated for BMP-4 and BMP-7. Related trials have been conducted in the sheep femur and rabbit tibia and ulna. ${ }^{52}$

The osteoinductive ability of BMP demonstrated in ex- traspinal animal models led to its utilization in animal models involving spinal fusion. Studies have been conducted of multiple animal species and using an array of fusion techniques. In contrast to the extraspinal animal studies, few spinal animal studies in which rodent models have been used, due to the technical difficulties of performing spinal fusions on such a small scale. Instead, rabbits have been used extensively for spinal fusion studies, as their vertebral column size allows practical spinal procedures. One drawback of using the rabbit model has been the significant daily variation in the rabbit calcium homeostasis. ${ }^{9,51}$ As bone formation requires calcification of the extracellular matrix, such variations make interpreting data from rabbit studies somewhat difficult. Despite this limitation, multiple rabbit studies support the function of BMP in spinal fusion, particularly using a PLIT arthrodesis model.

\section{Posterolateral Intertransverse Models}

The first rabbit PLIT models were used to study the utility of implanting BMP in various carriers. Schimandle, et al. ${ }^{60}$ treated 56 rabbits at L5-6 with either rhBMP-2 of varying doses or autograft. Successful fusion was achieved in all rabbits that underwent BMP implantation while 


\section{H. Walker and N. M. Wright}

those augmented with autograft only a $42 \%$ fusion rate was achieved. Within the BMP group, stronger and more mature fusion masses were noted with higher doses (2.7 mg compared with $0.7 \mathrm{mg}$ ) and with the use of a collagen carrier, as determined by radiographic and histological analysis. Similar results were reported by Holliger, et al., ${ }^{23}$ when using CT scanning. Minamide, et al., ${ }^{39}$ performed PLIT at L4-5 in rabbits and compared rhBMP-2 transported in a sintered bovine bone and type I collagen complex to either autograft or sintered bone alone and again confirmed higher fusion when using rhBMP-2. In addition, histological analysis demonstrated both membranous and endochondral bone formation between the transverse processes and the fusion mass in the BMP group, whereas only continuous trabecular bone formation was noted in the other groups. Other studies performed in which varying carriers were used have continued to confirm higher fusion rates with rhBMP-2 in the rabbit PLIT model ${ }^{38,63}$ when compared with autograft.

Canine models of PLIT have also been extensively used to demonstrate the efficacy of BMP. Lovell, et al., ${ }^{30}$ evaluated the role of partially purified BMP (a nonrecombinant mixture of BMP subtypes isolated from bone) in a polyLlactic acid carrier when using the PLIT approach in the lower thoracic spine in 13 mongrel dogs. Four levels were studied in each animal with an intact motion segment between each level, with three control levels of decortication alone, decortication and autograft, or carrier and autograft. The BMP-treated levels had higher fusion rates relative to controls. Although not all BMP-treated levels fused, greater amounts of bone formation were seen in each of these levels compared with controls. The authors concluded that other carriers may be more suitable because the polyLlactic acid carrier was not resorbed, although authors of other studies have shown $100 \%$ fusion rates by using rhBMP-2 with the same carrier, ${ }^{45,56}$ albeit with an increased amount of void in the fusion mass when using a polyLactic acid carrier. ${ }^{14,15}$

Helm, et al., ${ }^{21}$ compared rhBMP-2 with either type I collagen gel or DBM, all in addition to autograft, in a canine model and demonstrated significantly higher fusion rates when using rhBMP-2 in addition to autograft. Sandhu, et al., ${ }^{55}$ studied the effects of varying doses of rhBMP2 by using the PLIT technique, with doses of 58 to $920 \mathrm{mg}$ carried in a polyLlactic acid polymer carrier. Successful fusion was achieved in all dogs by 3 months and no mechanical, radiographic, or histological differences in the quality of fusion were found despite a 40-fold variation in dosage. In the canine PLIT models, rhBMP-2 increased fusion rates either as an adjuvant to autograft or as a bone graft substitute.

The efficacy of rhBMP-2 has also been evaluated in nonhuman primates by using the PLIT model. Boden, et al., 5 studied 21 adult rhesus monkeys that underwent implantation with autograft or with increasing doses of rhBMP-2 in an hydroxyapatite-tricalcium phosphate carrier. At 24 weeks postimplantation, no animal treated with autograft showed evidence of fusion by inspection, radiography, or histological analysis. Monkeys treated with the carrier alone demonstrated bone formation between the transverse processes and carrier, but no bone formation into the carrier. All animals treated with rhBMP-2 demonstrated fusion in a dose-dependent fashion, both between the transverse processes and carrier and into the carrier itself. The same group later demonstrated improved fusion when carriers containing less hydroxyapatite were used. ${ }^{63}$ In the nonhuman primate, the fusion rate when using rhBMP-2 clearly exceeds that of autograft in PLIT models.

\section{Thoracic and Lumbar Interbody Models}

Posterior and anterior interbody fusions have been performed in several animal models that demonstrated the osteoinductive effects of BMP. Magin, et al., ${ }^{31}$ performed PLIF with monosegmental instrumentation and autograft, hydroxyapatite, or rhBMP-7 (rhOP-1) in 33 sheep. Fusion was not successful in the animals treated with hydroxyapatite, whereas all fusion was successful in sheep treated with rhBMP-7. Intervertebral fusion was demonstrated in most animals treated with autograft, but with a lower quality of bone healing and in a more delayed fashion than in those treated with rhBMP-7. The BMP treatment sites demonstrated remarkably dense bone with cortex like structure seen on pathological evaluation.

Cunningham, et al., ${ }^{11}$ evaluated rhBMP-7 (rhOP-1) in anterior interbody fusions in 12 sheep, comparing BAK/ rhBMP-7 to discectomy alone, empty BAK, autograft alone, and BAK/autograft. Although no group was seen to achieve $100 \%$ fusion, BAK/rhBMP-7 was at least as efficacious as BAK/autograft or autograft alone. Interestingly, in this model, discectomy or empty BAK also produced fusion rates of 17 to $33 \%$. Sandhu, et al., ${ }^{59}$ studied a sheep model of anterior lumbar interbody fusion with a threaded cage filled with either autograft or rhBMP-2 in a collagen carrier and reported a threefold increase in fusion with rhBMP-2.

Boden, et al., ${ }^{4}$ performed laparoscopic anterior spinal arthrodesis in eight rhesus monkeys by using a titanium interbody cage filled with increasing dosages of rhBMP-2 $(0-1.5 \mathrm{mg} / \mathrm{ml})$ in a collagen sponge carrier. Although all monkeys had some bone formation, only those treated with BMP were found to have continuous bone growth through the cages. A similar study in six rhesus monkeys was conducted by Hecht, et al., ${ }^{18}$ in which anterior lumbar interbody fusion was performed using a smooth cortical bone dowel packed with either autograft or rhBMP-2 in a collagen sponge carrier. In the rhBMP-2 group, the cortical bone dowel itself was also soaked in rhBMP-2 prior to insertion as well as being packed with the rhBMP-2/collagen sponge. Successful fusion occurred in only one of the control animals whereas extensive fusion was demonstrated in all of the BMP-treated animals. In lumbar and thoracic animal models of interbody fusion, rhBMP-2 and rhBMP-7 treatment resulted in higher fusion rates than with autograft.

\section{Cervical Interbody Fusion Models}

Few studies have been conducted in which the authors looked at anterior cervical fusions performed with BMP in animal models, perhaps due to the high baseline fusion rates seen in humans with either autograft or allograft. Two studies of anterior cervical fusion in the ovine model have supported the osteoinductive effects of rhBMP-2. Zdeblick, et al., ${ }^{72}$ performed three-level anterior cervical 
discectomies and fusions in a total of 21 Alpine goats by using a titanium BAK device filled with autograft, a BAK device coated with hydroxyapatite and filled with autograft, or a BAK device filled with rhBMP-2 in a collagen sponge carrier. A $95 \%$ fusion rate was documented in the BMP treated animals relative to $48 \%$ for the BAK/autograft group, and $62 \%$ for the hydroxyapatite-coated BAK/ autograft group. In this model of cervical interbody fusion, rhBMP-2 increased both the rate of fusion as well as the quality of fusion in BAK cages.

Takahashi, et al., ${ }^{64}$ examined the effect of the dose of rhBMP-2 on cervical interbody fusion in the ovine model. Fourteen goats underwent three-level anterior cervical discectomies and fusion with hydroxyapatite grafts filled with $5 \mu \mathrm{g}$ or $50 \mu \mathrm{g}$ of rhBMP-2 or hydroxyapatite grafts without rhBMP-2. All animals treated with the higher dose of rhBMP-2 had successful fusion whereas both the animals treated with the lower dose as well as the animals treated with hydroxyapatite grafts alone only had a $50 \%$ fusion rate. In the ovine cervical interbody model, successful fusion may require a certain threshold dose of rhBMP-2.

\section{Novel Delivery Strategies for BMP}

The dose of BMP required to effect osteoinduction dramatically increases in higher animals. Animal models have shown that although $0.05 \mathrm{mg} \mathrm{BMP} / \mathrm{g}$ of matrix is sufficient to heal long-bone defects in the rabbit, $1.2 \mathrm{mg}$ is required in the canine and $2.5 \mathrm{mg}$ in the nonhuman primate. ${ }^{53}$ Despite the increased availability of BMP with recombinant technology, concerns remain about implanting such supraphysiological doses of BMP. As BMPs are rapidly degraded once released from the site of implantation, one strategy has been to prolong the duration of secretion of BMP.

In an attempt to prolong the effects of BMP, researchers have turned to gene therapy to produce cells which themselves manufacture the desired BMP molecules. Riew and colleagues, ${ }^{10,51}$ used an adenoviral vector to transduce rabbit marrow-derived mesenchymal cells with the gene for human BMP-2. After transduction, these cells were shown to have increased alkaline phosphatase activity and to express increased levels of messenger RNA for BMP-2 as well as type I collagen, osteopontin, and osteocalcin compared with native mesenchymal cells. Additionally, transduced cells were able to induce matrix mineralization in vitro. These cells were used for autologous implantation in a rabbit PLIT model and new bone formation has been demonstrated. The same technique has been replicated in the porcine thoracoscopic fusion model and interbody fusion demonstrated after implantation of transduced marrow cells carrying the gene for human BMP-2 into the minimally disrupted thoracic intervertebral disc (manuscript in preparation) (Figs. 2-3). Thus, cells producing minute, physiological quantities of BMP-2 over a longer period of time may be as osteoinductive as a single implant of a larger, supraphysiological quantity of BMP.

Using similar techniques, Wang, et al., evaluated the degree of fusion effected by implanting marrow-derived mesenchymal cells transduced with the gene for BMP-2 with the fusion effected by implanting rhBMP-2 (Wang JC, et al: Gene therapy for spinal fusion: transformation of marrow cells with an adenoviral vector to produce BMP2, presented at the Scoliosis Research Society Annual Meeting; San Diego, California, 1999). Both preparations produced $100 \%$ fusion, confirming that physiological delivery of BMP-2 is at least as effective as the implantation of supraphysiological of amounts rhBMP-2. Percutaneous injections of adenoviral constructs containing either the gene for BMP- $2^{1}$ or BMP-9 ${ }^{19}$ have also produced bone formation in rat models.

Boden, et al., ${ }^{3}$ approached the problem from a different angle. They identified, cloned, and sequenced a novel cDNA encoding for an intracellular protein LIM mineralization protein-1 (LMP-1), which is expressed during the first few hours of osteoblast differentiation. The protein LMP-1 induces BMPs, their receptors and other bone growth factors. Local implantation of bone marrow cells transfected with LMP-1 cDNA induced spine fusion in the rat model. These experiments highlight potential therapies that manipulate the natural cascade of growth factors and promise exciting developments in the field of spinal fusion.

\section{High-Risk Fusion Models}

Although one of the lures of BMP therapies is to increase the fusion rates in patients at risk of fusion nonunion, such as smokers, most animal studies of BMP fusion augmentation have been conducted under ideal conditions with healthy animals, and properly prepared surgical fusion sites. Three studies have been conducted in which fusion rates in animal models with BMP augmentation have been examined in less than ideal situations: without decortication of osseous elements; concurrent treatment with ketorolac; and concurrent treatment with nicotine.

Sandhu, et al., ${ }^{57}$ examined intertransverse process fusion rates in 20 dogs by using three doses of rhBMP-2 ranging from 58 to $920 \mu \mathrm{g}$ in a polyLlactic acid carrier. In half of the animals the transverse processes, facets, and laminae were decorticated prior to implantation of rhBMP-2 and in half the fusion site was not decorticated. There were no statistical differences in clinical or radiographically demonstrated fusion rates between corticated and decorticated sites; however, the group with the lowest dose of BMP-2 failed to achieve solid bilateral arthrodeses when the spine was not decorticated prior to implantation, suggesting that higher doses of BMP may be required in suboptimal fusion conditions.

The deleterious effects of NSAIDs in the setting of spinal fusion are well-studied. To ascertain the effect of NSAIDs on BMP, Martin, et al., ${ }^{33}$ used the PLIT model in rabbits treated with either saline or $4 \mathrm{mg} / \mathrm{kg} / \mathrm{day}$ of the NSAID ketorolac delivered by an implanted subcutaneous pump for 7 days postoperatively. Animals underwent a single-level arthrodesis with either autograft alone or autograft soaked in $3 \mathrm{mg}$ of rhBMP- 2 for 5 minutes. Control animals treated with saline and autograft had a fusion rate of $75 \%$. In the animals receiving ketorolac, fusion rates of $35 \%$ were noted in animals treated with autograft alone and $100 \%$ in those that received autograft and rhBMP-2. Not only do these results reaffirm the adverse effects of NSAIDs on spinal arthrodesis, but also suggest that higher doses of rhBMP-2 may overcome the inhibitory effects of NSAIDs. 


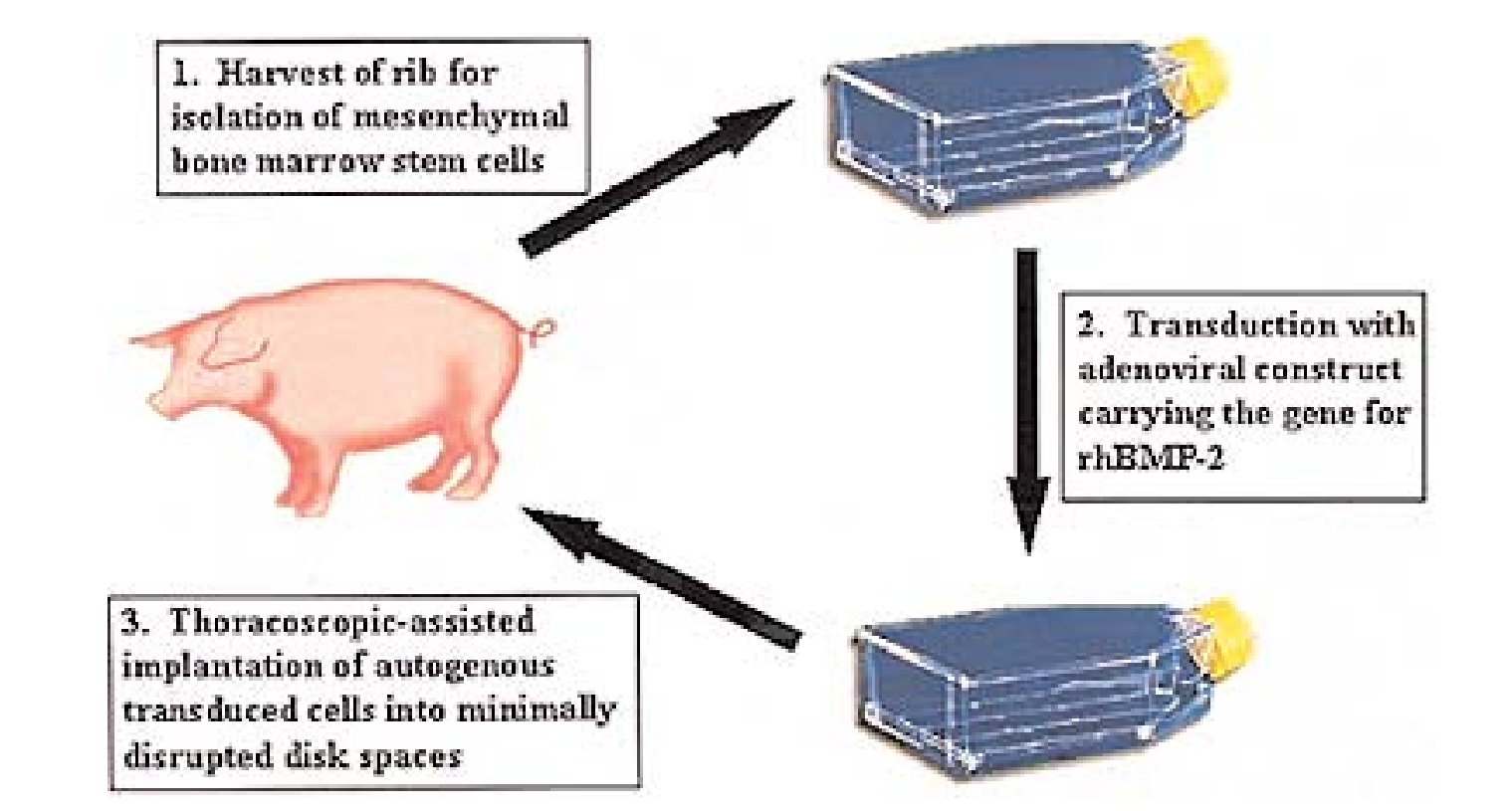

Fig. 2. Schematic drawing of a minimally-invasive animal thoracic interbody fusion model in which an adenoviralBMP construct is used. In the first surgery, a rib is removed from each pig for harvesting of mesenchymal bone marrow stem cells. These cells are grown in culture and then transduced with an adenoviral construct carrying the gene for rhBMP-2. After transduction, a second surgery using the thoracoscopic technique is performed to implant these cells autologously into a minimally disrupted disc space.

Nicotine was evaluated in a similar fashion in a rabbit PLIT model. ${ }^{62}$ Nicotine was administered with an implantable subcutaneous pump for 5 to 10 weeks postoperatively at a rate that approximated smoking 20 to 30 cigarettes a day. Fusion was then compared among animals receiving autograft alone, osteoinductive bone protein extract with DBM, or osteoinductive bone protein extract with autograft. None of the autograft group demonstrated fusion, confirming the inhibitory effect of nicotine on arthrodesis. Sixty-four percent of the osteoinductive protein/DBM and $100 \%$ of the osteoinductive protein/autograft groups demonstrated fusion. This study showed that the inhibitory effect of nicotine could be overcome by an osteoinductive protein in an animal model.

\section{Animal Models of BMP Safety}

Although BMP clearly increases the quality as well as the degree of bone formation in both posterolateral and interbody spinal fusion models, one clinical concern has been the safety of using BMP in proximity to nervous structures. Boden, et al., 5 studied the effect in 21 rhesus monkeys of laminectomy in the setting of BMP implantation. Two-level laminectomies were performed prior to posterolateral intertransverse arthrodesis with rhBMP-2. Manual inspection, radiographic analysis, and histological examination failed to detect any significant encroachment of bone formation into the laminectomy defect in any of the animals. Similar results were reported in a related study by the same authors when using a different rhBMP2 delivery system. ${ }^{32}$ These limited studies suggest that BMP placement in the posterolateral aspect of the spine may be feasible even in the setting of laminectomy with exposed dura; however, direct implantation of BMP onto the ligamentum flavum has been shown to induce spinal stenosis. ${ }^{37,40}$
Authors of two animal studies have explored the effect of dural perforation on use of BMP in spinal arthrodesis. Meyer, et al., ${ }^{36}$ studied the safety of rhBMP-2 in the setting of dural opening in a canine model. After laminectomy, either autograft or $0.24 \mathrm{mg}$ of rhBMP-2 in a collagen carrier was placed over the laminectomy defect following perforation of the dura by using a 22-gauge needle, with documented egress of cerebrospinal fluid. After 12 weeks, radiographic examination revealed bone formation in the laminectomy defect in both controls and in the rhBMP-2 group; however, more bone was formed in all dimensions in the rhBMP-2 group. In no animal was there radiographic evidence of bone formation within the dura. On histological examination, both groups had evidence of minor mineralization of the dural membrane but no evidence of intradural ossification. All animals remained neurologically normal.

In another canine model of dural perforation, Paramore, et al., ${ }^{48}$ studied the safety of rhBMP-7 (rhOP-1) use. After laminectomy, the dura was opened to simulate an intraoperative dural rent. The rhBMP-7 was then placed in both the posterolateral intertransverse space and in the subarachnoid space. Inspection at 16 weeks revealed bone formation in the subarachnoid space with compression of the spinal cord. Additionally, exuberant extradural bone formation was found at the laminectomy site, which caused mild spinal stenosis in all rhBMP-7 treated animals. The safety of the use of BMP in these animal models make several findings are clear. Although BMP clearly improves the degree and quality of arthrodesis, caution must be used in the setting of laminectomy or dural laceration. Although these studies provide conflicting results on the safety of rhBMP-2 and rhBMP-7 in the setting of laminectomy, intradural placement of rhBMP-7 resulted in significant ossification of the spinal cord. 


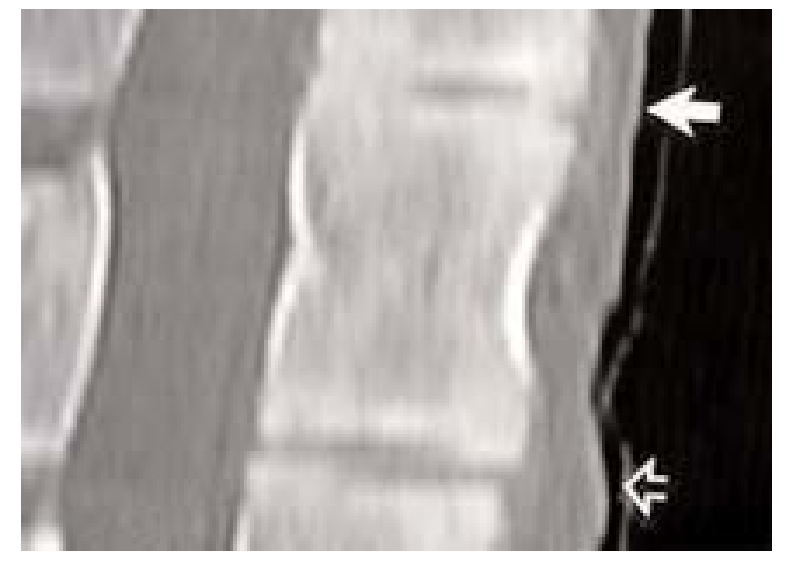

Fig. 3. A CT scan with sagittal reconstruction through isolated pig spines 8 weeks after implantation of mesenchymal bone marrow cells transduced with an adenoviral construct carrying the gene for rhBMP-2 (Adv-BMP). A normal intervertebral disc space is shown (open arrow) as well as a disc space after implantation of Adv-BMP cells (solid arrow) in which bridging bone is seen.

\section{Animal Models of Nonrecombinant BMP}

Semipurified human BMP extracts have been reported in the treatment of segmental long-bone defects ${ }^{25}$ and have been used in salvage spine surgery (J. P. Johnson, personal communication). In one recent study the authors report use of a highly purified bovine BMP extract, bBMPx, in spinal animal models. ${ }^{13}$ In the first part of this study, 45 rabbits underwent placement of autograft or varying doses of bBMPx in a PLIT model of spinal arthrodesis in the setting of laminectomy. With higher doses of bBMPx, complete fusion was seen, whereas the control group had a $62 \%$ fusion rate. Equal numbers of complications were seen in both the bBMPx and autograft groups. In the second part of the study, 48 rhesus monkeys underwent placement of either autograft or varying doses of bBMPx implanted in a similar PLIT model. Even with higher doses of bBMPx, only a 54\% fusion rate was seen by 24 weeks, although this was higher than the $21 \%$ fusion rate seen in the autograft controls. The third part of the study evaluated the safety of bBMPx in a laminectomy model in six rhesus monkeys and found no evidence of thecal compression with use of bBMPx.

Although whole BMP perhaps provides the advantage of delivering all of the various BMP subtypes rather than a single subtype, its isolation from bone inherently carries with it a similar risk to that of any allograft, albeit low: transmission of infectious disease. Recombinant proteins obviate this risk and therefore have had more appeal for clinical trials.

\section{CLINICAL TRIALS WITH BMP}

Following the multitude of animal studies demonstrating dramatic increases in fusion mass and quality with the use of rBMP and the documentation of relative safety of use, clinical trials in humans began. Although animal studies have shown osteoinduction with various BMP subtypes, including rhBMP-2, rhBMP-7, and rhBMP-9 as well as whole BMP extract from human bone, clinical tri- als have primarily been limited to rhBMP- 2 and rhBMP7 (rhOP-1).

\section{Clinical Trials of Whole BMP Extract}

Although no outcomes have yet been reported, in one recent paper the authors ${ }^{13}$ mention an ongoing pilot study of a highly purified bovine BMP extract, bBMPx (NeOsteo; Sulzer Biologics, Austin, TX) in a human posterolateral intertransverse model. The investigators in this study have enrolled 22 patients and report using up to 50 $\mathrm{mg}$ of bBMPx on one side and using the patient's autograft on the contralateral side as an internal control. The patients will be followed radiographically and clinically for 24 months by using the outcome measures of fusion rate, morphology, and quality.

\section{Clinical Trials With rhBMP-7 (rhOP-1)}

Three clinical trials in humans have been reported in which rhBMP-7 (rhOP-1) was used in posterolateral intertransverse arthrodesis. ${ }^{69}$ As these trials have been presented in abstract form at spine meetings but not yet published, an adequate review of the scientific method, materials, outcomes, and conclusions of each is not yet possible. Patel, et al., recently reported a safety and efficacy study of rhBMP-7 in 16 patients with degenerative lumbar spondylolisthesis and spinal stenosis (Patel TC, et al: A pilot safety and efficacy study of OP-1 (rhBMP-7) in posterolateral lumbar fusion as a replacement for iliac crest autograft, presented at the North American Spine Society Annual Meeting; Seattle, Washington, 2001). Patients were randomized to receive either autograft alone in a posterolateral arthrodesis or autograft and $3.5 \mathrm{mg}$ of rhBMP-7 in a carrier of $1 \mathrm{~g}$ of bovine bone collagen and $230 \mathrm{mg}$ of carboxymethylcellulose (OP-1 Putty; Stryker Biotech, Hopkinton, MA). No instrumentation was placed in any patient. Radiographic evaluation at 6 months with static and dynamic radiography revealed a $75 \%$ fusion rate in the rhBMP-7 group with only a 50\% fusion rate in the group receiving autograft alone, although this did not reach statistical significance. Clinical assessment using Oswestry scores revealed a trend favoring the patients in whom rhBMP-7 was used, although this also did not reach statistical significance; no complications were reported.

A small series of five patients receiving rhBMP-7 for the treatment of degenerative spondylolisthesis and spinal stenosis has been recently presented (Speck G: Using OP1: a model using degenerative spondylolithesis, presented at the Australian Spine Meeting, Adelaide, Australia, 2000). ${ }^{69}$ All patients underwent autograft placement unilaterally in a posterolateral intertransverse arthrodesis after lumbar decompression with the contralateral side receiving $3.5 \mathrm{mg}$ of rhBMP-7 in a carrier of $1 \mathrm{~g}$ of bovine bone collagen and $230 \mathrm{mg}$ of carboxymethylcellulose, without supplementary autograft. Radiographic evaluation with CT scanning at 6 months revealed equal or greater bone formation on the side receiving rhBMP-7.

In the United States, a prospective, randomized, multicenter trial is underway to determine the success of rhBMP-7 in the setting of degenerative spondylolisthesis and lumbar stenosis. ${ }^{69}$ After decompression, patients are randomized to receive bilateral, noninstrumented, posterolateral intertransverse arthrodesis with either autograft 
alone or $3.5 \mathrm{mg}$ of rhBMP-7 in a carrier of $1 \mathrm{~g}$ of bovine bone collagen and $230 \mathrm{mg}$ of carboxymethylcellulose. Outcome measures include Oswestry score improvement of more than $20 \%$, fusion as defined by bridging bone, and absence of motion on dynamic radiographs. Preliminary results suggest a trend toward better clinical success in the rhBMP-7 group.

\section{Clinical Trials With rhBMP-2}

By far the majority of clinical data regarding the use of BMP in human spinal models has involved the use of rhBMP-2. Nearly 500 patients have received rhBMP-2 as part of the clinical trials, ${ }^{34}$ leading in July, 2002 to the FDA approval of rhBMP-2 (InFUSE Bone Graft/LTCAGE Lumbar Tapered Fusion Device; Medtronic Sofamor-Danek, Memphis, TN) for use in ALIF. Clinical trials in humans involving the use of rhBMP-2 have been reported for ALIF, PLIF, PLIT, and anterior cervical interbody fusion.

Anterior Lumbar Interbody Fusion Trial With rhBMP-2. In a pilot study by Boden, et al., ${ }^{7} 14$ patients with single-level lumbar degenerative disc disease were randomized for treatment with ALIF, performed via a standard or laparoscopic approach, using a tapered, threaded cylindrical titanium cage filled with either autogenous iliac crest bone graft or rhBMP-2 in a collagen sponge carrier composed of bovine type I collagen. Eleven patients received rhBMP- 2 and 3 served as controls. The total dose of rhBMP-2 per cage varied from 1.95 to $3.9 \mathrm{mg}$, depending on the internal size of the threaded cage used; the concentration of rhBMP-2 remained constant at $1.5 \mathrm{mg} / \mathrm{ml}$ regardless of the size of cage implanted. All enrolled patients experienced more than 6 months of symptoms refractory to conservative measures, singlelevel disease, no higher than a Grade I spondylolisthesis, and confirmation of degenerative disc disease by radiographic abnormality (loss of disc height, end-plate sclerosis, or osteophytes), or provocative discography. Outcomes were determined by static and dynamic radiography, CT scanning with sagittal reconstructions, Oswestry scores, neurological status, pain medication usage, and comparison of hospital and operative informatics.

Statistically significant findings included shorter operative times in the rhBMP-2 group as no autogenous bone graft was harvested. Blood loss was less in the rhBMP-2 group, although this did not reach statistical significance. One patient in the rhBMP-2 group suffered a wound dehiscence and one control patient had postoperative urinary retention. Five independent radiologists evaluated imaging at 3, 6, 12, and 24 months postoperatively. In the rhBMP-2 group, 10 of 11 patients were found to have solid fusion by 3 months, and all 11 had solid fusion by 6 months. In the control group, two of the three patients were found to have fusion by 3 months, and fusion had not occurred in the third patient at the completion of the study 24 months later. There was a trend toward faster and more noteworthy improvements in Oswestry scores in the rhBMP-2 group, but this did not quite reach statistical significance. No meaningful difference between the two groups was seen in neurological status or pain medication usage.

Based on the promising results of the pilot study, a mul- ticenter, prospective, randomized trial of rhBMP-2 for ALIF was initiated in $1998 .{ }^{34} \mathrm{~A}$ total of 279 patients were enrolled, with 143 receiving rhBMP-2 according to enrollment criteria and operative procedures similar to those of the pilot study discussed previously, with the exception that all surgeries were performed in an open rather than a laparoscopic fashion. Outcome analysis was based on fusion as evidenced by plain radiographs and fine-cut CT scans, Oswestry scores, and operative and hospital informatics.

Within this pivotal study, total operative time and blood loss was lower in the rhBMP-2 group; however, although this was statistically significant, both total time and blood loss were low in both groups. No significant differences in Oswestry scores between the rhBMP-2 and control groups were seen at any time point. Related to the harvesting of autogenous bone, $32 \%$ of the control group continued to complain of pain at the iliac crest donor site 2 years postoperatively. Fusion rates were higher in the rhBMP-2 group at the 6,12, and 24 month evaluations. At the conclusion of the study, a $94.5 \%$ fusion rate was seen in the rhBMP-2 group compared with an $88.7 \%$ rate in the control group. Based on the results of this pivotal study, as well as the safety profile of rhBMP-2, FDA approval was granted in 2002 for use of rhBMP-2 (InFUSE Bone Graft) in the treatment of single-level degenerative disc disease in the lower lumbar spine.

Given the success of rhBMP-2 with the use of a threaded tapered cylindrical titanium cage, the efficacy of using rhBMP-2 implanted within a cortical threaded allograft bone dowel was evaluated in a study using similar methods as described ${ }^{34}$ and the results were presented in $a b-$ stract form (Burkus JK, et al: A prospective randomized study assessing the clinical and radiographic outcomes of patients treated with rhBMP-2 and threaded cortical bone dowels in the lumbar spine, presented at the North American Spine Society Annual Meeting, New Orleans, Louisiana, 2000). Using an open approach for single-level ALIF, threaded cortical bone dowels packed with either autogenous iliac crest bone graft or rhBMP-2 (InFUSE Bone Graft) were inserted. Forty-five patients were enrolled in the study, with 22 receiving rhBMP-2. Although the operative times were similar, much less blood loss was seen in the rhBMP-2 group. The rhBMP-2 group showed statistically more improvement in Oswestry scores than did the controls at 3 and 6 months, although the statistical significance was lost at 12 months. Fusion was seen in more patients and at earlier times in the rhBMP-2 group than in controls.

Laparoscopic ALIF With rhBMP-2. A supplementary arm of the pivotal study in which rhBMP-2 in ALIF was studied related to the results of implanting rhBMP-2 and the threaded tapered cylindrical cages laparoscopically rather than with an open approach (Zdeblick TA, et al: Laparoscopic approach with tapered metal cages: rhBMP2 vs. autograft, presented at the North American Spine Society Annual Meeting, Seattle, Washington, 2001). Similar methods and doses of rhBMP-2 were used in this trial to those in the main pivotal study. In this multicenter, prospective pivotal study, all 136 patients received rhBMP-2 for the treatment of single-level degenerative disease and were compared with historical controls from 
both a study of the same implant filled with autogenous iliac crest bone graft implanted laparoscopically and a study using the open approach.

The operative time was similar to those for the open approach, as was the total blood loss. Hospital length of stay was dramatically shorter in the laparoscopic rhBMP-2 group. Fusion rates were similar to those seen in both control groups at the 12-month time point, and 24-month fusion rates are not yet available for review.

Kleeman, et al., ${ }^{29}$ reported on their experience with 22 patients treated laparoscopically with NOVUS LT Cages (Sofamor Danek) and $4.9 \mathrm{mg}$ of rhBMP-2 in a sponge composed of bovine type I collagen. This was a case series and not a randomized study; no controls were used. All patients had refractory low back pain and confirmation of degenerative disc disease by radiography, magnetic resonance imaging, or discography. All but two patients did not smoke cigarettes. Clinical outcome measures of Oswestry score, neurological status, narcotic use, and evaluation of fusion with both static and dynamic radiography and CT scanning were performed at 6 and 12 months. Two complications occurred as a result of the laparoscopic approach and no complications were identified from use of rhBMP-2. All patients had improvement in Oswestry scores by at least 15 points by 12 months. Radiographically document fusion was seen in all patients by 6 months.

Posterior Lumbar Interbody Fusion With rhBMP-2. Alexander, et al., recently reported the preliminary data from a pilot study in which they evaluated the use of rhBMP-2 in a PLIF (Alexander JT, et al: An analysis of the use of rhBMP-2 in PLIF constructs: clinical and radiographic outcomes, presented at the American Association of Neurological Surgeons and Congress of Neurological Surgeons Joint Section on Disorders of the Spine and Peripheral Nerves Annual Meeting, Orlando, Florida, 2002). Seventy-one patients were enrolled in the study and underwent lumbar decompression for single-level degenerative lumbar disease followed by placement of cylindrical, hollow, threaded cages (INTERFIX; Medtronic Sofamor Danek) as stand-alone devices without supplementary pedicle screw fixation. In 36 patients the cages were packed with autogenous bone graft and in 35 they were packed with rhBMP-2 (InFUSE Bone Graft). Outcome measures consisted of Oswestry scores, hospital informatics, and radiographic analysis of fusion.

As with other clinical trials in which rhBMP-2 has been used, the hospital stay was shorter for the rhBMP-2 group than for controls. No significant difference in Oswestry scores was found between the two groups. Interestingly, fusion rates were lower in the rhBMP-2 group than in the control group (device and autogenous iliac crest bone graft). At 12 months, fusion rates in the two groups were 84 and $90.5 \%$, respectively. More alarming, exuberant heterotopic bone formation posterior to the interbody devices and extending into the spinal canal, along the tract of insertion, was seen in some patients receiving rhBMP-2. No clinical consequences resulting from this induced spinal stenosis have been reported, but the trial has been suspended.

Posterolateral Intertransverse Fusion With rhBMP-2. A single pilot study in Mexico of rhBMP-2 use in a posterolate.ral intertransverse process arthrodesis has been re- ported. ${ }^{34}$ Fifteen patients were enrolled in two groups. The first group of seven patients received $15 \mathrm{mg}$ of rhBMP-2 in a biphasic calcium phosphate carrier unilaterally and autogenous bone graft contralaterally. The second group of eight patients received $20 \mathrm{mg}$ of rhBMP- 2 in the same carrier bilaterally. Of note, this dose of rhBMP-2 represents a nearly 10 -fold increase compared with clinical trials of ALIF. Outcome measures included Oswestry scores and radiographic examination at intervals up to 12 months.

Eighty-seven percent of the first group had clinical success by 12 months as defined by improvement in Oswestry scores of at least 15 points, compared with $100 \%$ of the second group. Incomplete fusion was seen in Group 1 even at 12 months, although fusion was more likely on the side receiving rhBMP (86\%) than autograft (57\%). All patients in Group 2 evidenced fusion by 12 months.

Studies are currently ongoing in the United States regarding the use of rhBMP-2 in posterolateral intertransverse process arthrodesis.

Anterior Cervical Interbody Fusion With rhBMP-2. A single, multicenter clinical study of rhBMP-2 in anterior cervical interbody fusion has been reported. ${ }^{34}$ Thirty-three patients were enrolled, with 18 receiving machined fibular ring grafts (Cornerstone; Medtronic Sofamor Danek) filled with rhBMP-2 (InFUSE Bone Graft) and 15 receiving the same allograft filled with autogenous iliac crest bone graft. Comparable numbers of single-level and twolevel procedures were performed in each group. Demographics were also comparable.

Although blood loss was low throughout, the rhBMP-2 group had statistically significant less blood loss than controls, which was related to the morbidity of iliac crest harvest. At 3 months, donor site pain was negligible in the control group. Fusion rates of $100 \%$ were seen in both rhBMP-2 and control groups.

\section{POTENTIAL COMPLICATIONS OF USE IN SPINAL SURGERY}

\section{Overzealous Bone Formation}

One concern regarding the nonjudicious use of BMP in the clinical setting to induce or augment spinal arthrodesis is the danger of heterotopic bone formation. Overzealous bone formation can potentially result in symptomatic compression of the thecal sac or exiting nerve roots, calcification of the spinal cord or nerve roots, or unintended fusion of adjacent spinal segments. Review of the normal physiology of bone healing suggests how introduction of large amounts of BMP can potentially cause heterotopic bone formation.

Just as the introduction of other rh proteins such as insulin can alter cellular physiology, the introduction of supraphysiological doses of BMP can override the normal autoregulation of osteoinduction. Although local cellular in vivo levels of BMP are in the nanogram range, clinical studies have used milligram amounts of rBMP, six orders of magnitude difference. Expression of BMP-2 is likely self-regulated through negative feedback, and several inhibitory proteins have been identified in the process of BMP-mediated osteoinduction, including BMP-3,12 and 
the inhibitory Smad proteins, Smad-6 and Smad-7.24,41 Early work suggests that expression of these inhibitory proteins is increased by exposure of the cell to BMP-2, implicating them in a negative feedback system regulating the osteoinductive effects of BMP-2. The introduction of millionfold higher levels of BMP than normally seen at the cellular level unquestionably overrides the normal negative autoregulation and allows unrestricted osteoinduction. Recombinant BMP-driven osteoinduction, in the absence of effective autoregulation, may facilitate unwanted overzealous bone formation.

As shown by animal studies and clinical trials, this risk is far from theoretical. Although placement of rhBMP- $2^{5}$ or bovine whole BMP extract ${ }^{13}$ in the posterolateral location in an animal laminectomy model did not result in any significant encroachment of bone into the laminectomy defect, undesired bone formation was seen directly over the laminectomy defect with placement of rhBMP$2^{36}$ or rhBMP-7. ${ }^{48}$ Other models have induced spinal stenosis by direct implantation of BMP over the ligamentum flavum. ${ }^{37,40}$ In the setting of dural laceration in animal models, significant intradural bone formation and calcification of the spinal cord was seen with rhBMP-74, but not with rhBMP- $2,{ }^{36}$ although the studies were not of similar design.

Only one of the clinical trials in humans demonstrated untoward bone formation. Implantation of rhBMP-2 by using a PLIF approach resulted in heterotopic bone formation into the spinal canal along the insertion tract in a number of patients, ${ }^{34}$ although reportedly no patient developed symptoms of spinal stenosis. The trial was halted and rhBMP-2 is not currently approved for use in PLIF. Although no heterotopic bone formation was seen in the rhBMP-2 ALIF, laparoscopic ALIF, or PLIT trials, some heterotopic bone formation was seen anterior to the spinal column in the anterior cervical interbody trial. Although fewer patients have been enrolled in rhBMP-7 clinical trials, no heterotopic bone formation has yet been reported.

\section{Antibody Formation}

While overzealous bone formation constitutes a localized complication of BMP use, antibody formation against implanted BMP may represent a potential systemic complication. Antibody formation by the immune system occurs in response to introduction of external proteins or antigens and is in part related to both the amount of antigen and the duration of exposure. As such, proteins that are cleared quickly from the circulation are less likely to promote an antibody response compared with proteins that have longer clearance times. Early data suggest that rhBMP-2 is rapidly cleared from circulation, ${ }^{49}$ whereas rhBMP-7 clearance may be somewhat slower.

Antibody formation to rhBMP-2 has been negligible in the multiple clinical trials in humans. In the largest pivotal study of rhBMP-2 when using the ALIF model in 279 patients, antibody formation to rhBMP-2 was $0.7 \%$ in patients receiving rhBMP-2 and $0.8 \%$ in controls. ${ }^{34}$ In the same study, the incidence of antibody formation to the bovine type I collagen carrier was $13.1 \%$ for the investigational group and $12.9 \%$ in controls. In the laparoscopic arm of the pivotal study, the rate of antibody formation to rhBMP-2 was also $0.8 \%$ in the rhBMP-2 group, whereas
$24.8 \%$ developed antibodies to the bovine type I collagen carrier. None of the patients in whom antibodies to the bovine collagen carrier were identified developed antibodies to human type I collagen.

Early data suggest a much higher BMP antibody formation in rhBMP-7 trials. Although trials of rhBMP-7 (rhOP-1) are ongoing, early data suggest a 38\% antibody formation in patients treated with rhBMP-7 (European Public Assessment Report on Osteogenic Protein 1, from the Committee for Proprietary Medicinal Products, European Agency for the Evaluation of Medicinal Products, 2001). Antibody formation, although in a high number of patients, appears transient, with low titers. Although the reasons for increased antibody formation with rhBMP-7 remain unclear, increased clearance time from the circulation may be responsible.

Although no adverse effects have been yet reported with antibody formation to either rhBMP-2 or rhBMP-7, such antibody formation is worrisome. At a minimum, antibody formation likely limits future treatments with the same BMP subtype in patients in whom antibodies are detected. Subsequent exposure to the same antigen would likely induce a significant immune response. Routine postoperative serological evaluation may be indicated, especially in patients receiving rhBMP-7, if ongoing trials confirm these preliminary findings to prevent further applications in sensitized patients.

Bone morphogenetic protein has been implicated in many roles other than osteoinduction and may play a key role in multiple cellular processes in many tissues and organs. Accordingly, antibody formation to such intrinsic human proteins becomes more ominous. As the nonosteoinductive roles of BMP become clearer, the negative implications of antibody formation and possible development of an autoimmune response become more troubling.

These potential complications are not mentioned to temper the excitement regarding the development of BMP products, but rather to encourage their judicious and thoughtful use. Not only must the clinician be aware about these potential complications, but the patient should be educated of these possibilities in the process of obtaining informed consent.

\section{FUTURE DIRECTIONS}

Over the last three decades, BMP research has progressed from the initial isolation by Urist of an osteoinductive substance to the approval of a recombinant BMP product for use in spinal arthrodesis. Although BMP development has already reached the operating room, current research on osteoinduction promises additional developments that are likely to further increase the role of biologics in the clinical care of spinal patients. These research lines include investigations into the interactions between the various BMP subtypes; the interactions between BMP and BMP receptors; pharmacological manipulation of BMP-induced osteoinduction; and upstream regulators of BMP.

Current clinical trials have primarily focused on the effects of single recombinant subtypes, either rhBMP-2 or rhBMP-7, and required markedly supraphysiological doses in the milligram range for effective osteoinduction; how- 
ever, multiple subtypes of BMP have been shown to be osteoinductive. Optimal osteoinduction by using more physiological dosing of BMP likely requires a complex temporal interaction of these subtypes. Indeed, using reverse transcription-polymerase chain reaction, Morone, et al., ${ }^{43}$ studied the temporal expression of BMP-2, BMP-4, and BMP-6 mRNA in a rabbit model of posterolateral arthrodesis. Expression of BMP-2 began immediately after surgery, with a second peak of expression 5 weeks later; expression of BMP-4 was more delayed, at 1 week; expression of BMP-6 was maximal during the 3rd week after surgery. Physiological osteoinduction appears to involve a complex interaction between minute amounts of different BMP subtypes in a temporal fashion. Human and bovine whole BMP extracts may reproduce the delivery of multiple BMP subtypes, ${ }^{13}$ but not their temporal expression.

Ongoing research also suggests a complex interaction between the BMP subtypes and BMP receptors. Different combinations of BMP ligands and BMP receptors appear to produce cellular responses of varying intensity and form. ${ }^{17,46}$ Gilboa, et al., ${ }^{17}$ have shown that BMP receptors can exist in both homodimer and heterodimer forms in the absence of ligand, allowing for increased flexibility of response to stimulation by BMP. Furthermore, the response to BMP-2 occurs through different pathways, depending on the interaction between BMP-I and BMP-II receptors. ${ }^{46}$ Early evidence points to possible pharmacological manipulation of the BMP receptor interactions with cholesterol lowering agents, with potential effects on osteoinduction.

Some non-BMP molecules have also been shown to promote osteoinduction and hold promise for clinical use. Boden, et al., ${ }^{6}$ isolated an intracellular protein, LMP-1, and have used gene therapy to promote osteoinduction with LMP-1. The complex process of osteoinduction likely reflects more than the simple interaction of a limited number of BMP subtypes or other proteins and other components of the osteoinductive process likely remain undiscovered. Further research will help elucidate more fully the physiological process of osteoinduction and suggest how the process can be more effectively manipulated for clinical benefit.

\section{CONCLUSIONS}

Bone morphogenetic proteins have been proven to be potent osteoinductive agents through their effects on mesenchymal stem cells. Multiple animal studies in a variety of species and spinal arthrodesis models have demonstrated the efficacy of rhBMP subtypes in osteoinduction as a supplementation to autograft or as a bone graft substitute. Limited clinical trials in humans of whole BMP extract and rhBMP-7 (rhOP-1) show promise in inducing successful spinal fusion. More extensive clinical trials of rhBMP-2 have proven both its efficacy and safety in human spinal applications leading to the recent approval of rhBMP-2 by the FDA for certain applications in the lumbar spine.

The application of BMP not only increases the degree and quality of bone fusion in spinal arthrodesis models, potentially replacing bone grafting, but it also increases the successful fusion rates in models of high-risk fusion such as with concurrent nicotine or NSAID use. The application of BMP may allow spinal arthrodesis in patients who are otherwise at too high a risk for fusion nonunion, and it may increase the success rates in the tobacco abuse population.

We know that BMP must be used judiciously and carefully as overzealous bone formation can occur, especially if used adjacent to neural structures or in the setting of dural laceration; rhBMP-7, and to a lesser extent rhBMP2, also stimulates the formation of anti-BMP antibodies. Although no clinical sequelae of these antibodies have been observed, the development of antibodies against a naturally occurring human protein raises some concern regarding the long-term effects of rBMP use.

Although heralding a new era of spinal surgery, BMP should not be viewed as the final step in the introduction of biologics into spinal surgery, but rather as an important step forward. Future research promises to further refine the manipulation of the osteoinductive process and provide more biological tools to the spine surgeon.

\section{References}

1. Alden TD, Pittman DD, Beres EJ, et al: Percutaneous spinal fusion using bone morphogenetic protein-2 gene therapy. J Neurosurg 90:109-114, 1999

2. Bahamonde ME, Lyons KM: BMP3: to be or not to be a BMP. J Bone Joint Surg Am 83-A (Suppl 1):56-62, 2001

3. Boden SD: Biology of lumbar spine fusion and use of bone graft substitutes: present, future, and next generation. Tissue Eng 6: 383-399, 2000

4. Boden SD, Martin GJ Jr, Horton WC, et al: Laparoscopic anterior spinal arthrodesis with rhBMP-2 in a titanium interbody threaded cage. J Spinal Disord 11:95-101, 1998

5. Boden SD, Martin GJ Jr, Morone MA, et al: Posterolateral lumbar intertransverse process spine arthrodesis with recombinant human bone morphogenetic protein 2/hydroxyapatite-tricalcium phosphate after laminectomy in the nonhuman primate. Spine 24:1179-1185, 1999

6. Boden SD, Titus L, Hair G, et al: Lumbar spine fusion by local gene therapy with a cDNA encoding a novel osteoinductive protein (LMP-1). Spine 23:2486-2492, 1998

7. Boden SD, Zdeblick TA, Sandhu HS, et al: The use of rhBMP2 in interbody fusion cages. Definitive evidence of osteoinduction in humans: a preliminary report. Spine 25:376-381, 2000

8. Bostrom K, Watson KE, Horn S, et al: Bone morphogenetic protein expression in human atherosclerotic lesions. J Clin Invest 91:1800-1809, 1993

9. Bourdeau JE, Hesselton RA: Serum calcium concentrations in wild rabbits. Miner Electrolyte Metab 14:253-256, 1988

10. Cheng SL, Lou J, Wright NM, et al: In vitro and in vivo induction of bone formation using a recombinant adenoviral vector carrying the human BMP-2 gene. Calcif Tissue Int 68:87-94, 2001

11. Cunningham BW, Kanayama M, Parker LM, et al: Osteogenic protein versus autologous interbody arthrodesis in the sheep thoracic spine. A comparative endoscopic study using the Bagby and Kuslich interbody fusion device. Spine 24:509-518, 1999

12. Daluiski A, Engstrand T, Bahamonde ME, et al: Bone morphogenetic protein-3 is a negative regulator of bone density. Nat Genet 27:84-88, 2001

13. Damien CJ, Grob D, Boden SD, et al: Purified bovine BMP extract and collagen for spine arthrodesis: preclinical safety and efficacy. Spine 27 (Suppl 1):50-58, 2002

14. David SM, Gruber HE, Meyer RA Jr, et al: Lumbar spinal fusion using recombinant human bone morphogenetic protein in the canine. A comparison of three dosages and two carriers. Spine 24:1973-1979, 1999 
15. Fischgrund JS, James SB, Chabot MC, et al: Augmentation of autograft using rhBMP-2 and different carrier media in the canine spinal fusion model. J Spinal Disord 10:467-472, 1997

16. Fujii M, Takeda K, Imamura T, et al: Roles of bone morphogenetic protein type I receptors and Smad proteins in osteoblast and chondroblast differentiation. Mol Biol Cell 10:3801-3813, 1999

17. Gilboa L, Nohe A, Geissendorfer T, et al: Bone morphogenetic protein receptor complexes on the surface of live cells: a new oligomerization mode for serine/threonine kinase receptors. Mol Biol Cell 11:1023-1035, 2000

18. Hecht BP, Fischgrund JS, Herkowitz HN, et al: The use of recombinant human bone morphogenetic protein 2 (rhBMP-2) to promote spinal fusion in a nonhuman primate anterior interbody fusion model. Spine 24:629-636, 1999

19. Helm GA, Alden TD, Beres EJ, et al: Use of bone morphogenetic protein-9 gene therapy to induce spinal arthrodesis in the rodent. J Neurosurg 92:191-196, 2000

20. Helm GA, Alden TD, Sheehan JP, et al: Bone morphogenetic proteins and bone morphogenetic protein gene therapy in neurological surgery: a review. Neurosurgery 46:1213-1222, 2000

21. Helm GA, Sheehan JM, Sheehan JP, et al: Utilization of type I collagen gel, demineralized bone matrix, and bone morphogenetic protein-2 to enhance autologous bone lumbar spinal fusion. J Neurosurg 86:93-100, 1997

22. Hogan BL: Bone morphogenetic proteins: multifunctional regulators of vertebrate development. Genes Dev 10:1580-1594, 1996

23. Holliger EH, Trawick RH, Boden SD, et al: Morphology of the lumbar intertransverse process fusion mass in the rabbit model: a comparison between two bone graft materials - rhBMP-2 and autograft. J Spinal Disord 9:125-128, 1996

24. Itoh F, Asao H, Sugamura K, et al: Promoting bone morphogenetic protein signaling through negative regulation of inhibitory Smads. Embo J 20:4132-4142, 2001

25. Johnson EE, Urist MR: Human bone morphogenetic protein allografting for reconstruction of femoral nonunion. Clin Orthop 371:61-74, 2000

26. Kawabata M, Miyazono K: Bone morphogenetic proteins, in Canalis E (ed): Skeletal Growth Factors. Philadelphia: Lippincott Williams \& Wilkins, 2000, pp 269-290

27. Khalsa O, Yoon JW, Torres-Schumann S: TGF-beta/BMP superfamily members, Gbb-60A and Dpp, cooperate to provide pattern information and establish cell identity in the Drosophilia wing. Development 125:2723-2734, 1998

28. Kim IY, Lee DH, Ahn HJ, et al: Expression of bone morphogenetic protein receptors type-IA, -IB and -II correlates with tumor grade in human prostate cancer tissues. Cancer Res 60: 2840-2844, 2000

29. Kleeman TJ, Ahn UM, Talbot-Kleeman A: Laparoscopic anterior lumbar interbody fusion with rhBMP-2: a prospective study of clinical and radiographic outcomes. Spine 26: 2751-2756, 2001

30. Lovell TP, Dawson EG, Nilsson OS, et al: Augmentation of spinal fusion with bone morphogenetic protein in dogs. Clin Orthop:266-274, 1989

31. Magin MN, Delling G: Improved lumbar vertebral interbody fusion using rhOP-1: a comparison of autogenous bone graft, bovine hydroxylapatite (Bio-Oss), and BMP-7 (rhOP-1) in sheep. Spine 26:469-478, 2001

32. Martin GJ Jr, Boden SD, Marone MA, et al: Posterolateral intertransverse process spinal arthrodesis with rhBMP-2 in a nonhuman primate: important lessons learned regarding dose, carrier, and safety. J Spinal Disord 12:179-186, 1999

33. Martin GJ Jr, Boden SD, Titus L: Recombinant human bone morphogenetic protein-2 overcomes the inhibitory effect of ketorolac, a nonsteroidal anti-inflammatory drug (NSAID), on posterolateral lumbar intertransverse process spine fusion. Spine 24:2188-2194, 1999
34. McKay B, Sandhu HS: Use of recombinant human bone morphogenetic protein-2 in spinal fusion applications. Spine 27 (Suppl 1):66-85, 2002

35. Mehler MF, Mabie PC, Zhang D, et al: Bone morphogenetic proteins in the nervous system. Trends Neurosci 20:309-317, 1997

36. Meyer RA Jr, Gruber HE, Howard BA, et al: Safety of recombinant human bone morphogenetic protein-2 after spinal laminectomy in the dog. Spine 24:747-754, 1999

37. Mimatsu K, Kishi S, Hashizume Y: Experimental chronic compression on the spinal cord of the rabbit by ectopic bone formation in the ligamentum flavum with bone morphogenetic protein. Spinal Cord 35:740-746, 1997

38. Minamide A, Kawakami M, Hashizume H, et al: Evaluation of carriers of bone morphogenetic protein for spinal fusion. Spine 26:933-939, 2001

39. Minamide A, Tamaki T, Kawakami M, et al: Experimental spinal fusion using sintered bovine bone coated with type I collagen and recombinant human bone morphogenetic protein-2. Spine 24:1863-1872, 1999

40. Miyamoto S, Takaoka K, Yonenobu K, et al: Ossification of the ligamentum flavum induced by bone morphogenetic protein. An experimental study in mice. J Bone Joint Surg Br 74: 279-283, 1992

41. Miyazono K: Signal transduction by bone morphogenetic protein receptors: functional roles of Smad proteins. Bone 25: 91-93, 1999

42. Monsoro-Burq AH, Duprez D, Watanabe Y, et al: The role of bone morphogenetic proteins in vertebral development. Development 122:3607-3616, 1996

43. Morone MA, Boden SD, Hair G, et al: The Marshall R. Urist Young Investigator Award. Gene expression during autograft lumbar spine fusion and the effect of bone morphogenetic protein 2. Clin Orthop 351:252-265, 1998

44. Morse JH: Bone morphogenetic protein receptor 2 mutations in pulmonary hypertension. Chest 121 (Suppl 3):50-53, 2002

45. Muschler GF, Hyodo A, Manning T, et al: Evaluation of human bone morphogenetic protein 2 in a canine spinal fusion model. Clin Orthop 308:229-240, 1994

46. Nohe A, Hassel S, Ehrlich M, et al: The mode of bone morphogenetic protein (BMP) receptor oligomerization determines different BMP-2 signaling pathways. J Biol Chem 277: 5330-5338, 2002

47. Padgett RW, Wozney JM, Gelbart WM: Human BMP sequences can confer normal dorsal-ventral patterning in the Drosophilia embryo. Proc Natl Acad Sci USA 90:2905-2909, 1993

48. Paramore CG, Lauryssen C, Rauzzino MJ, et al: The safety of OP-1 for lumbar fusion with decompression - a canine study. Neurosurgery 44:1151-1156, 1999

49. Poynton AR, Lane JM: Safety profile for the clinical use of bone morphogenetic proteins in the spine. Spine 27 (Suppl 1): 40-48, 2002

50. Prolo DJ, Rodrigo JJ: Contemporary bone graft physiology and surgery. Clin Orthop 200:322-342, 1985

51. Riew KD, Wright NM, Cheng S, et al: Induction of bone formation using a recombinant adenoviral vector carrying the human BMP-2 gene in a rabbit spinal fusion model. Calcif Tissue Int 63:357-360, 1998

52. Riley EH, Lane JM, Urist MR, et al: Bone morphogenetic protein-2: biology and applications. Clin Orthop 324:39-46, 1996

53. Rosen V, Wozney JM: Bone morphogenetic proteins and the adult skeleton, in Canalis E (ed): Skeletal Growth Factors. Philadelphia: Lippincott Williams \& Wilkins, 2000, pp 299-310

54. Sampath TK, Coughlin JE, Whetstone RM, et al: Bovine osteogenic protein is composed of dimers of OP-1 and BMP-2A, two members of the transforming growth factor-beta superfamily. $\mathbf{J}$ Biol Chem 265:13198-13205, 1990

55. Sandhu HS, Kanim LE, Kabo JM, et al: Effective doses of re- 
combinant human bone morphogenetic protein-2 in experimental spinal fusion. Spine 21:2115-2122, 1996

56. Sandhu HS, Kanim LE, Kabo JM, et al: Evaluation of rhBMP2 with an OPLA carrier in a canine posterolateral (transverse process) spinal fusion model. Spine 20:2669-2682, 1995

57. Sandhu HS, Kanim LE, Toth JM, et al: Experimental spinal fusion with recombinant human bone morphogenetic protein-2 without decortication of osseous elements. Spine 22: 1171-1180, 1997

58. Sandhu HS, Khan SN: Animal models for preclinical assessment of bone morphogenetic proteins in the spine. Spine 27 (Suppl 1):32-38, 2002

59. Sandhu HS, Toth JM, Diwan AD, et al: Histologic evaluation of the efficacy of rhBMP-2 compared with autograft bone in sheep spinal anterior interbody fusion. Spine 27:567-575, 2002

60. Schimandle JH, Boden SD, Hutton WC: Experimental spinal fusion with recombinant human bone morphogenetic protein-2. Spine 20:1326-1337, 1995

61. Shoda A, Murakami K, Ueno N: Presence of high molecular weight forms of BMP-2 in early Xenopus embryos. Growth Factors 8:165-172, 1993

62. Silcox DH III, Boden SD, Schimandle JH, et al: Reversing the inhibitory effect of nicotine on spinal fusion using an osteoinductive protein extract. Spine 23:291-297, 1998

63. Suh DY, Boden SD, Louis-Ugbo J, et al: Delivery of recombinant human bone morphogenetic protein-2 using a compression-resistant matrix in posterolateral spine fusion in the rabbit and in the non-human primate. Spine 27:353-360, 2002

64. Takahashi T, Tominaga T, Watabe N, et al: Use of porous hydroxyapatite graft containing recombinant human bone morphogenetic protein-2 for cervical fusion in a caprine model. $\mathbf{J}$ Neurosurg 90 (Spine 4):224-230, 1999

65. Toriumi DM, Kotler HS, Luxenberg DP, et al: Mandibular reconstruction with a recombinant bone-inducing factor. Functional, histologic, and biomechanical evaluation.Arch Otolaryngol Neck Surg 117:1101-1112, 1991

66. Urist MR: Bone: formation by autoinduction. Science 150: 893-899, 1965

67. Urist MR: Bone transplantation, in Urist MR (ed): Fundamental and Clinical Bone Physiology. Philadelphia: JB Lippincott, 1980, pp 331-368

68. Urist MR, Huo YK, Brownell AG: Purification of bovine bone morphogenetic protein by hydoxyapatite chromotography. Proc Natl Acad Sci USA 81:371-375, 1984

69. Vaccaro AR, Anderson DG, Toth CA: Recombinant human osteogenic protein-1 (bone morphogenetic protein-7) as an osteoinductive agent in spinal fusion. Spine 27 (Suppl 1): 59-65, 2002

70. Wozney JM, Rosen V, Celeste AJ, et al: Novel regulators of bone formation: molecular clones and activitites. Science 242: 1528-1534, 1988

71. Yasko AW, Lane JM, Fellinger EF, et al: The healing of segmental bone defects, induced by recombinant human bone morphogenetic protein (rhBMP-2). A radiographic, histological, and biomechanical study in rats. J Bone Joint Surg Am 74: 659-670, 1992

72. Zdeblick TA, Ghanayem AJ, Rapoff AJ, et al: Cervical interbody fusion cages. An animal model with and without bone morphogenetic protein. Spine 23:758-766, 1998

Manuscript received October 10, 2002.

Accepted in final form November 20, 2002.

Address reprint requests to: Neill M. Wright, M.D., Department of Neurological Surgery, Washington University School of Medicine, 660 South Euclid Avenue, Box 8057, St. Louis, Missouri 63110. email: wrightn@nsurg.wustl.edu. 